\title{
Extração e exportação de nitrogênio, fósforo e potássio pelo milho adubado com dejetos de suínos
}

\author{
June Faria Scherrer Menezes ${ }^{1}$, Mariana Pina da Silva Berti², Valter Divino Vieira Júnior ${ }^{1}$, \\ Rênystton de Lima Ribeiro ${ }^{1}$, Christian Luis Ferreira Berti ${ }^{3}$

\footnotetext{
${ }^{1}$ Universidade de Rio Verde, campus de Rio Verde, Rio Verde, Goiás, Brasil. E-mail: june@ unirv.edu.br, renystton@hotmail.com.

${ }^{2}$ Universidade Estadual de Goiás, Campus de Ipameri, Ipameri, Goiás, Brasil. E-mail: mariana.berti@ueg.br

${ }^{3}$ Instituto Federal Goiano, Campus avançado de Catalão, Catalão, Goiás, Brasil. E-mail: profchristianluis@ gmail.com
}

Recebido: 04/05/2017; Aceito: 12/06/2018.

\section{RESUMO}

O objetivo deste trabalho foi avaliar a extração de nitrogênio (N), fósforo (P) e potássio (K) pela cultura do milho adubada com dejetos líquidos de suínos (DLS). O experimento foi conduzido no período de outubro de 2013 a abril de 2014, na Fazenda Fontes do Saber, localizada na Universidade de Rio Verde, Goiás. O experimento foi conduzido em um Latossolo Vermelho distroférrico de textura argilosa $\left(540 \mathrm{~g} \mathrm{~kg}^{-1}\right)$, e os tratamentos constituíram da aplicação ou não de DLS na dose de $30 \mathrm{~m}^{3}$ ha ${ }^{-1}$. Após a aplicação dos dejetos na superfície do solo foi feita a semeadura do milho e a partir das análises foliares avaliaram-se a extração de N, P e K pelas plantas de milho, em oito épocas, com intervalos médios de 15 dias, durante o ciclo de crescimento e desenvolvimento da cultura. Os resultados apontaram que o uso de DLS aumentou a produtividade de grãos do milho comparado ao tratamento controle (sem aplicação). A dose de $30 \mathrm{~m}^{3} \mathrm{ha}^{-1}$ de DLS com densidade de $1.013 \mathrm{~g} \mathrm{~cm}^{-3}$ é suficiente para resultar em produtividade de grãos acima de $9.000 \mathrm{~kg} \mathrm{ha}^{-1}$. A extração dos macronutrientes primários pela cultura do milho segue as seguintes ordens decrescente de absorção: $K>N>P$ e $N>K>P$, respectivamente, para o período vegetativo e reprodutivo.

Palavras-chave: Fertirrigação, nutrientes, resíduos orgânicos.

\section{Extraction and export of nitrogen, phosphorus and potassium by maize fertilized with pig slurry}

\begin{abstract}
The objective of this work was to evaluate the nitrogen $(\mathrm{N})$, phosphorus $(\mathrm{P})$ and potassium $(\mathrm{K})$ extraction by the maize crop fertilized with liquid pig manure (LPM). The experiment was carried out in a clayey Red Latosol (540 $\mathrm{g} \mathrm{kg}^{-1}$ ) from October 2013 to April 2014 at Fontes do Saber Farm, located at the University of Rio Verde, State of Goiás, Brazil. Treatments consisted of the application or not of liquid pig manure at the rate of $30 \mathrm{~m}^{3} \mathrm{ha}^{-1}$. After the manure application to the soil surface, the maize crop was sowing and the N, P and K extraction by the plants were evaluated in eight times, with mean intervals of 15 days, during the growth and development cycle of the crop. The results showed that the use of liquid pig manure increased maize grain yield compared to the control treatment (non-fertilized with manure). The rate of $30 \mathrm{~m}^{3} \mathrm{ha}^{-1}$ of liquid pig manure with density of $1013 \mathrm{~g} \mathrm{~cm}^{-3}$ is not sufficient to result in grain yields above $9000 \mathrm{~kg} \mathrm{ha}^{-1}$. The nutrient extraction by maize plants follows the decreasing order of absorption: $\mathrm{K}>\mathrm{N}>\mathrm{P}$ and period $\mathrm{N}>\mathrm{K}>\mathrm{P}$, respectively, for the vegetative and reproductive stage.
\end{abstract}

Keywords: Fertirrigation, nutrients, organic residues. 


\section{Introdução}

A cultura do milho apresenta alto potencial de produção no mundo, com aproximadamente 960 milhões de toneladas. A importância econômica dessa cultura é caracterizada pelas diversas formas de sua utilização, que vai desde a alimentação animal até a indústria de alta tecnologia. Porém, a produtividade brasileira é baixa (70 milhões de toneladas), quando comparada à da China (200 milhões de toneladas) e Estados Unidos (272 milhões de toneladas). Dentre os principais fatores que contribuem para a baixa produtividade do milho, destacam-se o clima, o potencial genético e o manejo de nutrientes e pragas (Hoeft, 2003).

Para o aumento da produtividade, há a necessidade de fornecimento de nutrientes por meio de fertilização do solo, podendo ser mineral ou orgânica. Uma das alternativas de adubação do solo no Sudoeste Goiano é a fertirrigação com dejetos suínos, pois na Região concentram-se granjas de produção de suínos em sistema de confinamento. $\mathrm{O}$ dejeto gerado dentro dessas unidades de produção deve retornar ao solo como uma forma de reciclagem e fonte de nutrientes para as plantas, possibilitando assim, incrementar a produção de grãos e reduzir os custos da lavoura.

A aplicação de dejeto de suínos (DS) vem se destacando como opção de descarte, podendo ser utilizada na adubação de culturas anuais, frutíferas, pastagens, reflorestamento e mesmo para recuperação de áreas degradadas (Ceretta et al., 2005; Barnabé et al., 2007; Medeiros et al., 2007; Seganfredo, 2007; Giacomini; AITA, 2008; Seidel et al., 2010; Gonzatto et al., 2013; Lourenzi et al.,2014; Somavilla et al., 2015; Silva et al., 2005; Menezes et al., 2017).

A utilização de dejeto de suínos (DS) nas lavouras pode contribuir no aumento de matéria orgânica e no nível de fertilidade do solo, com consequente aumento de produtividade da cultura do milho, pois esses resíduos são ricos em nutrientes (nitrogênio, fósforo, potássio, cobre, sódio, entre outros) e devem ser utilizados como uma adubação alternativa, desde que bem monitorado (Cavallet et al., 2006).

No presente trabalho, avaliou-se a eficácia da utilização de dejetos de suínos na produtividade e na extração e exportação de $\mathrm{N}$ (nitrogênio), $\mathrm{P}$ (fósforo) e K (potássio) pela cultura do milho cultivado em sistema de plantio direto.

\section{Material e Métodos}

O experimento foi conduzido no período de 25 de outubro de 2013 a 04 de abril de 2014, na Fazenda Fontes do Saber, na Universidade de Rio Verde, GO (17 $47^{\circ} 53^{\prime \prime} \mathrm{S}, 50^{\circ} 55^{\prime} 14$ ' $\mathrm{W}$ e altitude de $\left.715 \mathrm{~m}\right)$. A área experimental foi constituída por dois tratamentos, sendo dividido pela aplicação ou não de dejetos de suínos sobre resíduos culturais de soja, em sistema plantio direto.

O solo da área experimental é classificado como Latossolo Vermelho distroférrico de textura argilosa (540 $\mathrm{g} \mathrm{kg}^{-1}$ ). A área utilizada para implantação do experimento é destinada ao projeto "Monitoramento ambiental com o uso de resíduos orgânicos na agricultura". O solo foi amostrado antes e após a aplicação do dejeto de suínos, e os principais resultados da análise química do solo são apresentados na Tabela 1.

Tabela 1. Características químicas do solo da área experimental, provenientes da camada de 0 a $0,20 \mathrm{~m}$ de profundidade, coletadas antes e após a aplicação do dejeto de suínos. Rio Verde, GO. 2013/2014.

\begin{tabular}{lrr}
\hline \multirow{2}{*}{ Característica } & \multicolumn{2}{c}{ Amostra coletada } \\
\cline { 2 - 3 } & Antes & Depois \\
\hline $\mathrm{pH}\left(\mathrm{CaCl}_{2}\right)$ & 4,96 & 5,06 \\
$\mathrm{MO}\left(\mathrm{g} \mathrm{dm}^{-3}\right)$ & 21,25 & 24,49 \\
$\mathrm{P}\left(\mathrm{mg} \mathrm{dm}^{-3}\right)$ & 1,60 & 6,70 \\
$\mathrm{~K}\left(\mathrm{mg} \mathrm{dm}^{-3}\right)$ & 84,00 & 107,30 \\
$\mathrm{Ca}\left(\mathrm{cmol}_{\mathrm{c}} \mathrm{dm}^{-3}\right)$ & 1,23 & 1,60 \\
$\mathrm{Mg}\left(\mathrm{cmol}_{\mathrm{c}} \mathrm{dm}^{-3}\right)$ & 1,01 & 1,05 \\
$\mathrm{H}+\mathrm{Al}\left(\mathrm{cmol}_{\mathrm{c}} \mathrm{dm}^{-3}\right)$ & 5,60 & 6,10 \\
$\mathrm{CTC}\left(\mathrm{cmol}_{\mathrm{c}} \mathrm{dm}^{-3}\right)$ & 8,11 & 9,03 \\
$\mathrm{~V}(\%)$ & 30,17 & 32,31 \\
$\mathrm{Cu}\left(\mathrm{mg} \mathrm{dm}^{-3}\right)$ & 6,00 & 4,90 \\
$\mathrm{Fe}\left(\mathrm{mg} \mathrm{dm}^{-3}\right)$ & 56,00 & 59,80 \\
$\mathrm{Mn}\left(\mathrm{mg} \mathrm{dm}^{-3}\right)$ & 97,30 & 137,50 \\
$\mathrm{Zn}\left(\mathrm{mg} \mathrm{dm}^{-3}\right)$ & 2,60 & 4,40 \\
\hline
\end{tabular}

O resíduo orgânico foi proveniente de uma granja de criação de suínos do Sistema Vertical Terminador (SVT) e foram aplicados no dia 25 de outubro de 2013, por volta de 20 dias antes do plantio, a fim de esperar a reação do adubo orgânico e este começar a disponibilizar nutrientes ao solo e serem posteriormente absorvidos pelas plantas, sendo a dose utilizada de 30 $\mathrm{m}^{3} \mathrm{ha}^{-1}$. Os dejetos de suínos foram analisados quimicamente no laboratório de análises de solos, folhas e resíduos orgânicos da Universidade de Rio Verde. Pela análise química, o dejeto continha $0,27 \%$ de $\mathrm{N}$, $0,12 \%$ de $\mathrm{P}, 0,19 \%$ de $\mathrm{K}$ e $1.013 \mathrm{~g} \mathrm{~cm}^{-3}$ de densidade.

A semeadura do milho foi realizada no dia 14 de novembro de 2013 utilizando-se um híbrido de alta produtividade e recomendado para a região o CD 3590 $\mathrm{Hx}$, com espaçamento de $50 \mathrm{~cm}$ e população de $60 \mathrm{mil}$ plantas $\mathrm{ha}^{-1}$. Cada parcela era composta por 12 linhas, espaçadas por $50 \mathrm{~cm}$ e com $50 \mathrm{~m}$ de comprimento.

Durante o ciclo da cultura foram realizados todos os tratos culturais, a aplicação do herbicida foi realizada quando a cultura estava entre V2 à V3, utilizando-se o princípio ativo Tembotrione $240 \mathrm{~mL} \mathrm{ha}^{-1}$, Atrazina 2,5 $\mathrm{L} \mathrm{ha}^{-1}$ e Adjuvante (óleo vegetal) $1 \mathrm{~L} \mathrm{ha}^{-1}$. As aplicações de inseticidas foram realizadas em três aplicações, a 
primeira em pós-emergente (juntamente com o herbicida) e as outras duas aplicações com intervalos de dez dias, usando-se o princípio ativo Metomil 0,6 $\mathrm{L} \mathrm{ha}^{-1}$. As aplicações de fungicidas foram realizadas em V8 e V13, usando-se um produto com duplo modo de ação, tendo como princípios ativos Epoxiconazol e Piraclostrobina $0,5 \mathrm{~L} \mathrm{ha}^{-1}$ e óleo mineral $0,5 \mathrm{~L} \mathrm{ha}^{-1}$.

As coletas das plantas foram realizadas aos 20, 34, 51, 67, 81, 96, 113 e 131 dias após o plantio do milho (DAP). Foram realizadas oito amostragens durante o ciclo de desenvolvimento da cultura e cada amostra era composta por 5 plantas, sendo apenas parte aérea, eliminando-se as raízes. As partes aéreas das plantas foram coletadas de forma aleatória procurando-se amostrar plantas normais e representativas do bloco. As amostras foram coletadas de acordo com os estádios fenológicos, conforme Tabela 2.

Tabela 2. Estádios fenológicos das plantas de milho correspondentes às datas de coleta (DAP). Rio Verde, GO. 2013/2014.

\begin{tabular}{lc}
\hline Estádios Vegetativos & Dias após plantio (DAP) \\
\hline V4 - Quarta folha & 20 \\
V8 - Oitava folha & 34 \\
V13 - Décima terceira folha & 51 \\
V18 - Décima oitava folha & 67 \\
R1 - Florescimento final & 81 \\
R2 - Grão leitoso & 96 \\
R4 - Grão farináceo & 113 \\
R5 - Grão farináceo-duro & 131 \\
\hline
\end{tabular}

Após a coleta, as amostras das partes aéreas das plantas foram levadas para secagem na estufa de circulação forçada de ar até peso constante. Em seguida foram pesadas, para quantificar a massa de matéria seca. As plantas foram separadas em parte vegetativa (folhas e hastes) e, posteriormente, após o estádio R1, em parte reprodutiva (espigas $=$ grãos, sabugo e palha). Em seguida as diferentes partes das plantas foram moídas e submetidas às análises químicas no Laboratório de Análises de Solos, Folhas e Resíduos Orgânicos da Universidade de Rio Verde (LASF).

Nas amostras vegetais foram avaliados os teores de $\mathrm{N}$ (nitrogênio), $\mathrm{P}$ (fósforo) e $\mathrm{K}$ (potássio) em função da aplicação ou não do resíduo. As determinações foram realizadas conforme as metodologias descritas por Silva (2009).

A colheita dos grãos de milho foi realizada no dia 4 de abril de 2014, quando os grãos atingiram $18 \%$ de umidade e foi realizada manualmente, colhendo-se 6 linhas de 2,5 metros de comprimento, perfazendo uma área útil de 7,5 metros quadrados. Em seguida cada parcela foi trilhada mecanicamente sendo os grãos pesados e os dados transformados em quilogramas por hectare (13\% base úmida).

\section{Resultados e Discussão \\ Análise do dejeto de suíno}

As quantidades aplicadas de $\mathrm{N}, \mathrm{P}$ e $\mathrm{K}$ com a adubação de $30 \mathrm{~m}^{3} \mathrm{ha}^{-1}$ de dejeto foram $81 \mathrm{~kg} \mathrm{ha}^{-1}$ de $\mathrm{N}$, $36,6 \mathrm{~kg} \mathrm{ha}^{-1}$ de $\mathrm{P}\left(83,4 \mathrm{~kg} \mathrm{ha}^{-1}\right.$ de $\left.\mathrm{P}_{2} \mathrm{O}_{5}\right)$ e $58,2 \mathrm{~kg} \mathrm{ha}^{-1} \mathrm{de}$ $\mathrm{K}\left(69,8 \mathrm{~kg} \mathrm{ha}^{-1}\right.$ de $\left.\mathrm{K}_{2} \mathrm{O}\right)$. Segundo Souza e Lobato (2004), a adubação recomendada para a cultura do milho corresponde a $100 \mathrm{~kg} \mathrm{ha}^{-1}$ de $\mathrm{N}, 80 \mathrm{~kg} \mathrm{ha}^{-1}$ de $\mathrm{P}_{2} \mathrm{O}_{5}$ e $90 \mathrm{~kg} \mathrm{ha}^{-1}$ de $\mathrm{K}_{2} \mathrm{O}$. Com base nesta recomendação as quantidades de $\mathrm{N}_{\text {e }} \mathrm{K}_{2} \mathrm{O}$ provenientes dos dejetos líquidos de suínos não foram suficientes para suprir as exigências nutricionais de $\mathrm{N}$ e $\mathrm{K}$, faltando $19 \mathrm{~kg} \mathrm{ha}^{-1}$ de $\mathrm{N}$ e $20,2 \mathrm{~kg} \mathrm{ha}^{-1}$ de $\mathrm{K}_{2} \mathrm{O}$.

\section{Acúmulo de matéria seca}

A produção da matéria seca (MS) da parte aérea variou conforme o desenvolvimento da cultura, sendo maior com a aplicação de dejetos de suínos (Figura 1). Até os 80 dias após plantio a produção de MS foi semelhante nos dois tratamentos devido à planta estar no seu período vegetativo. Observa-se crescimento significativo aos 100 DAP, em função da planta estar no período reprodutivo, em que passa a ter um aumento significativo de massa devido ao desenvolvimento de espigas (grão + sabugo). Após esta época houve uma maior produção de MS nas plantas adubadas com dejetos, havendo um incremento de 30,15\% (Figura 1).

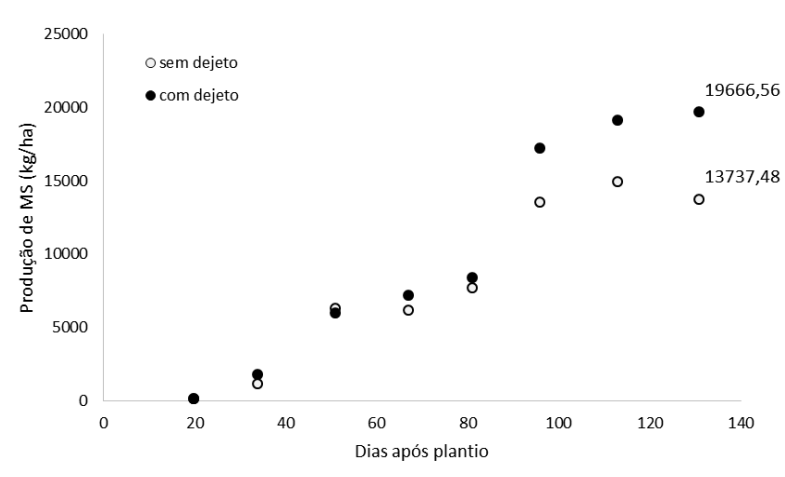

Figura 1. Produção de matéria seca da parte aérea de milho durante seu ciclo de desenvolvimento em função da aplicação ou não de dejeto de suínos. Rio Verde, GO. 2013/2014.

\section{Produtividade de grãos}

A dose de $30 \mathrm{~m}^{3} \mathrm{ha}^{-1}$ de dejetos de suínos aplicados ao solo contribuiu para a máxima produtividade de grãos de milho, correspondendo a $9.021 \mathrm{~kg} \mathrm{ha}^{-1}$. Essa produtividade foi $11 \%$ maior em comparação ao tratamento controle. A maior produtividade com a adubação de dejetos de suínos foi devido as plantas extraírem maiores disponibilidade de nutrientes (Figura 2). A produtividade de grãos no tratamento sem dejeto foi alta devido à área experimental apresentar um solo de alta fertilidade, em decorrência do histórico de 14 anos ocorrer a adubação com resíduos orgânicos. 


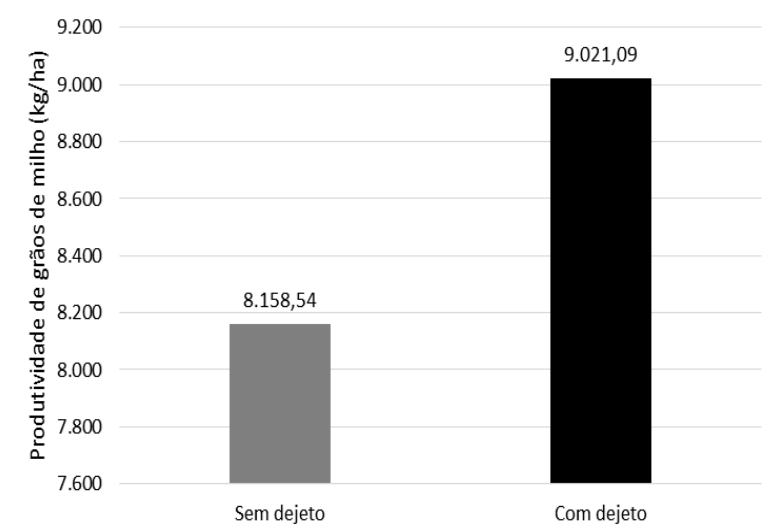

Figura 2. Produtividade de grãos de milho em função da aplicação ou não de dejetos de suínos. Rio Verde, GO. 2013/2014.

A massa de mil grãos com a aplicação de dejeto de suíno foi de $317,1 \mathrm{~g}$ e no tratamento sem adubação correspondeu a 292,4 g. Obtendo-se incremento de $8,45 \%$ na massa de mil grãos na área adubada com o resíduo. Estudos indicam que a adubação com dejetos de suínos é eficiente para a nutrição e produtividades das culturas, desde que seja aplicada uma dose adequada à exigência da cultura (Konzen, 2000, Ceretta et al., 2005, Scherer et al., 2007, Cavallet et al., 2006).

\subsection{Extração e exportação de nitrogênio, fósforo e potássio}

A extração de nitrogênio na parte aérea aos 20 DAP foi de $42 \mathrm{~g} \mathrm{~kg}^{-1}$ de MS com aplicação do dejeto e $28,4 \mathrm{~g}$ $\mathrm{kg}^{-1}$ de MS sem aplicação do resíduo. Nesta época, à planta está em pleno desenvolvimento vegetativo acumulando em média $70-80 \%$ matéria seca total (Figura 3). O acúmulo total de nitrogênio na parte aérea da planta foi de $179,2 \mathrm{~kg} \mathrm{ha}^{-1}$ com a aplicação do dejeto líquido de suínos e $162,08 \mathrm{~kg} \mathrm{ha}^{-1}$ de nitrogênio no tratamento sem adubação (Tabela 5).

$\mathrm{O}$ maior acúmulo de fósforo ocorreu no período reprodutivo, próximo da época de pendoamento. Porém houve uma exportação maior deste nutriente para os grãos, aos 113 dias após o plantio, no tratamento que não foi utilizado a adubação com dejetos, sendo exportados $6,7 \mathrm{~g} \mathrm{~kg}^{-1}$ de MS. As quantidades extraídas de fósforo nas plantas são bem menores em relação ao nitrogênio (Figura 4). A extração total de fósforo na parte aérea da planta foi de $70,97 \mathrm{~kg} \mathrm{ha}^{-1}$ com a aplicação do dejeto líquido de suínos e $53,30 \mathrm{~kg} \mathrm{ha}^{-1}$ de fósforo no tratamento sem adubação (Tabela 5).

Conforme dados na Tabela 5, observa-se que, a produtividade de grãos, a extração de $\mathrm{N}$ na parte aérea da cultura com a aplicação do resíduo orgânico, foram próximos aos obtidos por Bull (1993) (Tabela 2). Segundo Malavolta et al. (1997), a quantidade total de $\mathrm{N}, \mathrm{P}$ e K acumulados (grãos + restos culturais) seriam de 117,56 e $257 \mathrm{~kg} \mathrm{ha}^{-1}$ de N, P e K, respectivamente.

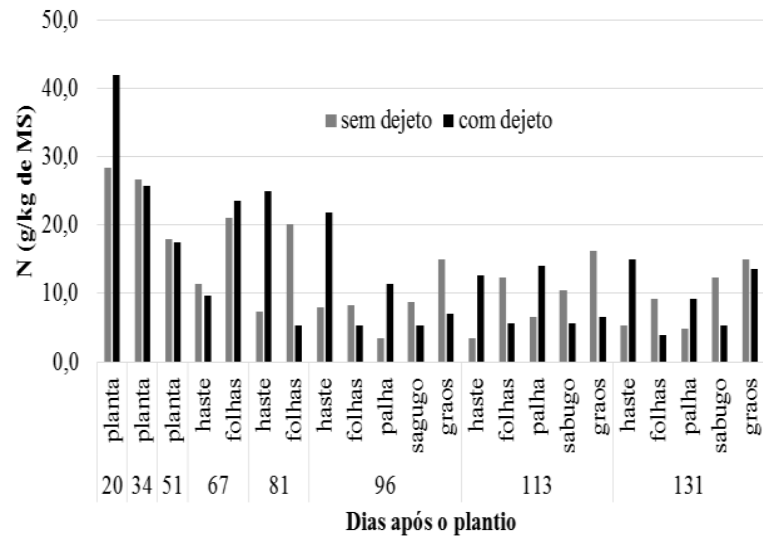

Figura 3. Teor de $\mathrm{N}$ na massa seca de milho durante seu ciclo de desenvolvimento em função da aplicação ou não de dejeto de suínos. Rio Verde, GO. 2013/2014.

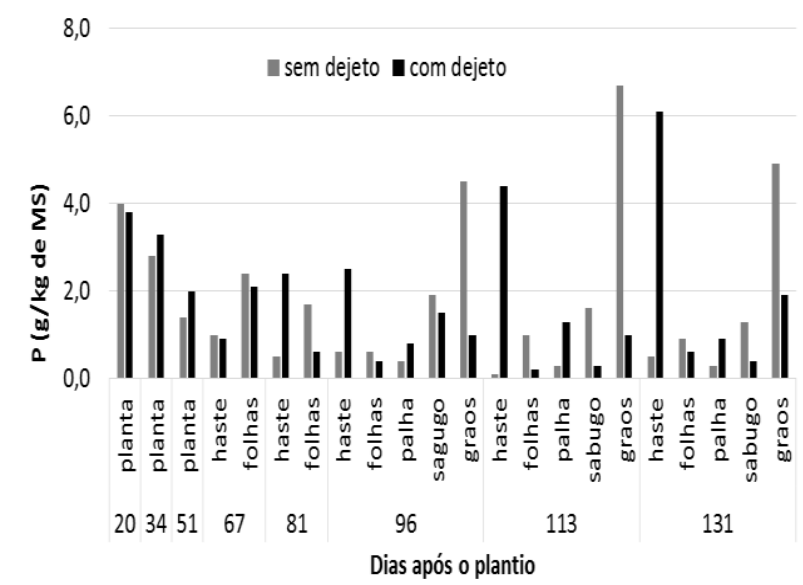

Figura 4. Teor de $\mathrm{P}$ na massa seca de milho durante seu ciclo de desenvolvimento em função da aplicação ou não de dejeto de suínos. Rio Verde, GO. 2013/2014.

A extração de potássio nos primeiros 34 DAP é elevada. A extração máxima de potássio em plantas jovens inteiras com aplicação de dejetos suínos foi de $48,5 \mathrm{~g} \mathrm{~kg}^{-1}$ de massa seca e $45,3 \mathrm{~g} \mathrm{~kg}^{-1}$ de massa seca (Figura 5). A extração total de potássio na parte aérea da planta foi de $86,60 \mathrm{~kg} \mathrm{ha}^{-1}$ com a aplicação do dejeto líquido de suínos e $65,27 \mathrm{~kg} \mathrm{ha}^{-1}$ de potássio no tratamento sem adubação (Tabela 5).

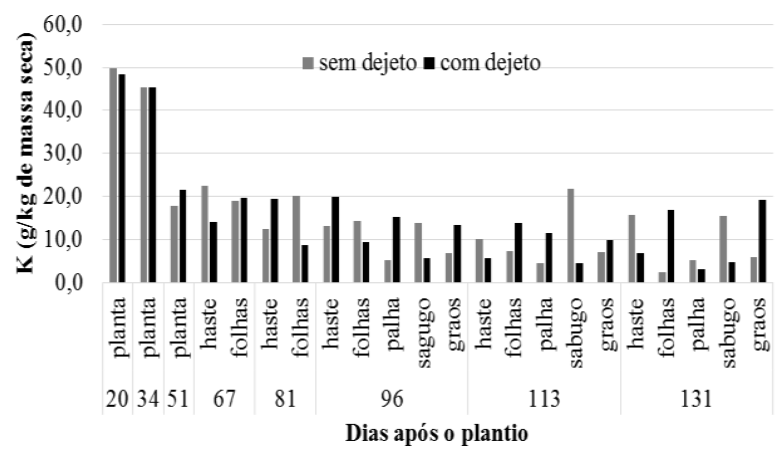

Figura 5. Teor de K na massa seca de milho durante seu ciclo de desenvolvimento em função da aplicação ou não de dejeto de suínos. Rio Verde, GO. 2013/2014. 
Tabela 5. Produtividades de grãos e matéria seca total, extração de macronutrientes na parte aérea do híbrido de milho - CD 3590 Hx. Rio Verde, GO. 2013/2014.

\begin{tabular}{|c|c|c|c|c|c|}
\hline Adubação & Grãos & MS & $\mathrm{N}$ & $\mathrm{P}$ & $\mathrm{K}$ \\
\hline & \multicolumn{2}{|c|}{$\mathrm{Mg} \mathrm{ha}^{-1}$} & \multicolumn{3}{|c|}{$\mathrm{kg} \mathrm{ha}^{-1}$} \\
\hline Sem dejeto & 8,16 & 13,7 & 121,56 & 48,14 & 58,74 \\
\hline \multirow[t]{3}{*}{ Com dejeto } & 9,02 & 19,7 & 134,41 & 44,20 & 54,13 \\
\hline & & & \multicolumn{3}{|c|}{ Concentração (\% na MS) } \\
\hline & & & $\mathrm{N}$ & $\mathrm{P}$ & $\mathrm{K}$ \\
\hline Sem dejeto & & & 1,26 & 0,18 & 1,56 \\
\hline Com dejeto & & & 1,33 & 0,19 & 1,50 \\
\hline
\end{tabular}

\section{CONCLUSÕES}

O uso dos dejetos de suínos aumenta a produtividade de grãos, porém, a dose de $30 \mathrm{~m}^{3} \mathrm{ha}^{-1}$ com densidade de $1.013 \mathrm{~g} \mathrm{~cm}^{-3}$ não é suficiente para resultar em produtividade de grãos superior à $9000 \mathrm{~kg} \mathrm{ha}^{-1}$.

A extração de nutrientes segue a ordem decrescente para o período vegetativo da cultura do milho $\mathrm{K}>\mathrm{N}>\mathrm{P}$ e no período reprodutivo $\mathrm{N}>\mathrm{K}>\mathrm{P}$.

\section{Referências Bibliográficas}

Barnabé, M. C., Rosa, B., Lopes, E. L., Rocha, G. P., Freitas, K. R., Pinheiro, E. P. 2007. Produção e composição químicobromatológica da Brachiaria brizantha cv. marandu adubada com dejetos líquidos de suínos. Ciência Animal Brasileira, 8, 435-446.

Büll, L. T. Nutrição mineral do milho. In: Büll, L. T., Cantarella, H. (eds.) Cultura do milho: fatores que afetam a produtividade. Piracicaba-SP, 1993. p. 63-146.

Cavallet, L. E., Lucchesi, L. A. C., Moraes, A., Schimidt, E., Erondi, M. A., Fonseca, R. A. 2006. Melhoria da fertilidade do solo decorrentes da adição de água residuária da indústria de enzimas. Revista Brasileira de Engenharia Agrícola e Ambiental, Campina Grande-PB, 10,724-729.

Ceretta, C. A., Basso, C. J., Pivinato, P. S., Trentin, E. E. Girotto, E. 2005. Produtividade de grãos de milho, produção de matéria seca e acúmulo de nitrogênio, fósforo e potássio na rotação aveia preta/milho/nabo forrageiro com aplicação de dejeto líquido de suínos. Ciência Rural, 35,1296-1304.

Giacomini, S. J., Aita, C. 2008. Cama sobreposta e dejetos líquidos de suínos como fonte de nitrogênio ao milho. Revista Brasileira Ciência do Solo, Viçosa-MG, 32, 195-205.

Gonzatto, R., Miola, E. C. C, Doneda, A., Pujol, S. B., Aita, C., Giacomini, S. J. 2013. Volatilização de amônia e emissão de óxido nitroso após aplicação de dejetos líquidos de suínos em solo cultivado com milho. Ciência Rural, 43, 590-1596.

Hoeft, R. G. 2003. Desafios para obtenção de altas produtividades de milho e soja nos EUA. Informações Agronômicas, 104, 1-4.

Konzen, E. A. 2000. Alternativas de manejo, tratamento e utilização de dejetos animais em sistemas integrados de produção. Sete Lagoas-MG: Embrapa Milho e Sorgo. 32 p. (Documentos, 5).
Lourenzi, C. R., Ceretta, C. A., Brunetto, G., Girotto, E., Tiecher, T. L., Vieira, r. C. B., Cancian, A., Ferreira, P. A. A. 2014. Pig slurry and nutrient accumulation and dry matter and grain yield in various crops. Revista Brasileira de Ciência do Solo, 38, 949-958.

Malavolta, E., Vitti, G. C., Oliveira, S. A. 1997. Avaliação do estado nutricional das plantas: princípios e aplicações. Piracicaba-SP: Potafós, 319p.

Medeiros, L. T., Rezende, A. V., Vieira, P. F., Cunha Neto, F. R., Valeriano, A. R., Casali, A. O., Gastaldello Junior, A. L. 2007. Produção e qualidade da forragem de capim-marandu fertirrigada com dejetos líquidos de suínos. Revista Brasileira de Zootecnia ,36, 309-318.

Menezes, J. F. S., Silva, M. P., Cantão, V. C. G., Caetano, J. O., Benites, V. M., Campos, G. W. B., Santos, B. L. R. 2017. Long-term application of swine manure on soybean grown in no-till system in Savannah soils. African Journal of Agricultural Research, 12, 487-493.

Scherer, E. E., Baldissera, I. T., Nesi, C. N. 2007. Propriedades químicas de um Latossolo Vermelho sob plantio direto e adubação com esterco de suínos. Revista Brasileira de Ciência do Solo, 31,123-131.

Seidel, E. P., Gonçalves Junior, A. C., Vanin, J. P., Strey, L., Schwantes, D., Nacke, H. 2010. Aplicação de dejetos de suínos na cultura do milho cultivado em sistema de plantio direto. Acta Scientiarum. Technology, 32, 113-117.

Seganfredo, M. A.2007. Uso dejetos suínos como fertilizantes e seus riscos ambientais. In: Gestão ambiental da suinocultura. Brasília-DF: Embrapa Informação Tecnológica. p.149-175.

Silva, E. C., Buzetti, S., Guimarães, G. L., Lazarini, E., Sá, M. E. 2005. Doses e épocas de aplicação de nitrogênio na cultura do milho em plantio direto sobre Latossolo Vermelho. Revista Brasileira de Ciência do Solo, 29, 353-362.

Souza, D. M. G., Lobato, E. 2004. Cerrado: correção do solo e adubação. 2. ed. Brasília-DF: Embrapa Cerrados. 416 p.

Silva, F. C. (Ed.). 2009. Manual de análises químicas de solos, plantas e fertilizantes. 2. ed. Brasília-DF: Embrapa Informação Tecnológica, Rio de Janeiro-RJ: Embrapa Solos.

Somavilla, L., Basso, C.J., Fabbris, C., Ros, O., Silva, V.R., Pinto, M.A.B., Brun, T., Demari, G.H. 2015. Ciclagem do nitrogênio pela parte aérea do milho submetido a doses de dejeto líquido de suínos. Bioscience Journal, 31, 481-488. 